\title{
Resolución del caso
}

\author{
Ricardo Trueba \\ Departamento de Resonancia y Tomografía Computada, Grupo Médico Rostagno, \\ Diagnóstico por Imágenes, Ciudad Autónoma de Buenos Aires, Argentina
}

Presentación del caso en la página 303.

\section{DIAGNÓSTICO: LESIÓN OSTEOCONDRAL DE ASTRÁGALO.}

\section{DISCUSIÓN}

Un defecto osteocondral es una lesión del cartílago y el hueso subcondral subyacente de una articulación. Se produce como consecuencia de un evento traumático, secundario a un esguince o una fractura de tobillo. Las causas secundarias incluyen enfermedad degenerativa, mala alineación articular, anomalías metabólicas y necrosis avascular. La mayoría de las lesiones en el astrágalo comprometen tanto el cartílago superficial como el hueso subyacente. Las lesiones puramente condrales son menos comunes. Son más frecuentes en el lado medial de la región central de la cúpula talar, donde son más grandes y profundas en comparación con su contraparte lateral.

Las molestias incapacitantes referidas por una población de pacientes jóvenes activos, junto con la limitada capacidad intrínseca de autocuración hacen de las lesiones osteocondrales de astrágalo un cuadro médico desafiante.

Los defectos pequeños muestran alguna reparación espontánea, en la cual el defecto está cubierto con un tejido fibroso similar. Este fibrocartílago tiene cualidades mecánicas inferiores debido a su estructura más simple y al menor contenido de glucosaminoglicanos. En el caso de defectos más grandes, el tejido de reparación puede volverse inestable y no puede llenar el defecto, lo que provoca dolor prolongado, una reacción inflamatoria y posiblemente osteoartritis con el tiempo.

La evaluación diagnóstica del paciente comienza con los antecedentes y el examen físico, distinguiendo el impacto del dolor profundo en el tobillo debido a una lesión osteocondral. Asimismo, se evalúan la estabilidad y la alineación del tobillo. Se solicitan radiografías convencionales anteroposterior, en mortaja y lateral de tobillo para determinar si hay una lesión osteocondral. También son útiles para identificar tanto los cambios degenerativos concomitantes, como la alineación del tobillo.

Sin embargo, aproximadamente el 50\% de las lesiones osteocondrales no se identifican en las radiografías convencionales y, a menudo, este estudio subestima el tamaño del defecto cuando se compara con la tomografía computarizada (TC). Las imágenes adicionales pueden proporcionar una mejor visualización de las dimensiones y la ubicación de una lesión. En la práctica clínica, la RM y la TC tienen una sensibilidad y una especificidad de buena a excelente para detectar una lesión osteocondral. La TC utiliza rayos X y crea imágenes tridimensionales del tobillo. Existen dos tipos de tomografías, la más conocida es la TC multicorte y la otra es la denominada TC de haz cónico (cone beam). La TC de haz cónico ofrece ventajas por sobre la TC multicorte: las imágenes tienen mejor resolución espacial, emite una baja dosis de radiación y produce pocos artefactos metálicos, es muy útil en pacientes ya intervenidos y con una osteosíntesis. Tradicionalmente, no es posible obtener imágenes del cartílago directamente sin un medio de contraste intrarticular adicional. Muestra, con precisión, la localización de las lesiones en el domo astragalino (Figura 4). Se utiliza un esquema de grilla anatómica propuesto por Raikin para ubicarlas. Las lesiones centrales son las más frecuentes seguidas de las centrales laterales. También se utiliza para determinar las dimensiones óseas de una lesión, la integridad de la placa ósea subcondral y la presencia de quistes subcondrales.

Dr. RICARDO TRUEBA • ricardotrueba@gmail.com ID https://orcid.org/0000-0001-7908-817X

Cómo citar este artículo: Trueba R. Instrucción Ortopédica de Posgrado - Imágenes. Resolución del caso. Rev Asoc Argent Ortop Traumatol 2020;85(4):447-450. http://dx.doi.org/ 10.15417/ issn. 1852-7434.2020.85.4.1198 


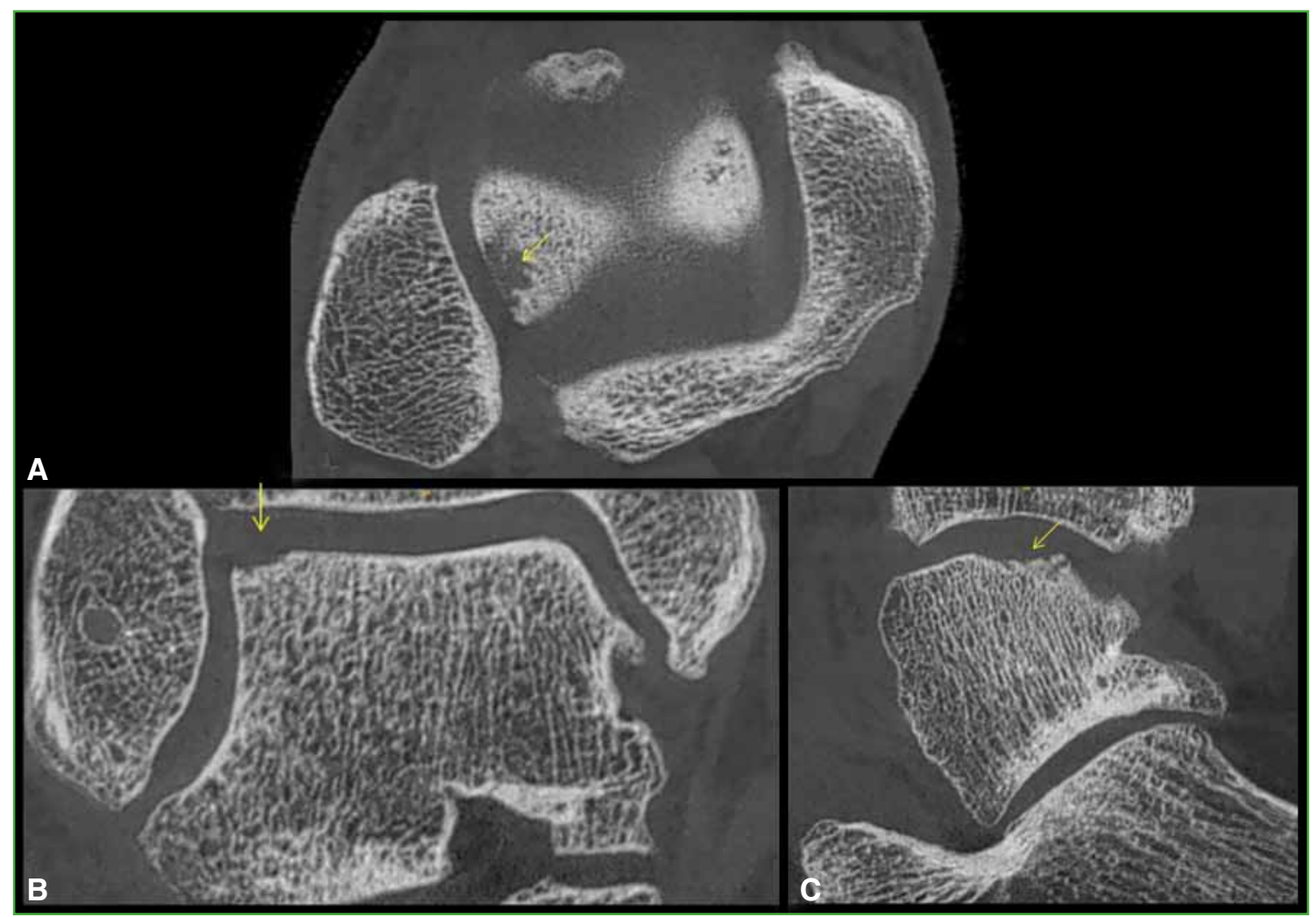

Figura 4. Tomografía computarizada de haz cónico, planos axial (A), coronal (B) y sagital (C) sin contraste.

Se observa una irregularidad ósea en el margen medial del domo astragalino.

Antes se consideraba que solo el ancho y el largo de la lesión osteocondral eran más importantes para definir una conducta, pero desde hace unos años, se le comenzó a dar mucho valor a la profundidad, junto con las otras dimensiones. Un ancho o un largo de $15 \mathrm{~mm}$ y una profundidad de $5 \mathrm{~mm}$ cambian la conducta terapéutica. Se argumenta que una lesión osteocondral dolorosa inherentemente indica un compromiso óseo, ya que las terminaciones nerviosas están situadas en el hueso y no en el cartílago, lo que hace que el hueso subcondral sea una estructura importante para la imagen. Finalmente, se ha demostrado que la TC es una herramienta útil de planificación preoperatoria, porque los cirujanos pueden evaluar el stock óseo disponible y planificar el acceso con una artroscopia anterior.

La clasificación de Ferkel y Sgaglione (1993) se basa en las imágenes de TC, y consta de 5 estadios.

Estadio I: Lesión quística, techo intacto

Estadio IIA: Lesión quística, con comunicación al domo astragalino

Estadio IIB: Lesión abierta de superficie articular, con fragmento no desplazado

Estadio III: Lesión abierta de la superficie articular, con fragmento no desplazado, con radiolucencia

Estadio IV: Fragmento desplazado

La RM utiliza un campo magnético con ondas electromagnéticas para compilar imágenes sin radiación ionizante. Es adecuada para detectar edema óseo y proporciona información detallada sobre los tejidos blandos, el cartílago y la estabilidad de una lesión. Asimismo, es capaz de obtener imágenes de pequeñas interrupciones en el cartílago, como las fisuras. La RM tiende a sobrestimar el tamaño de la lesión debido al edema óseo. Las mejoras en la resolución de las imágenes, las bobinas de tobillo y las secuencias adicionales que utilizan la supresión grasa ponderada en T2 o densidad protónica han contribuido a solucionar este problema. Además, las características morfológicas son más difíciles de visualizar en comparación con otras articulaciones, porque el cartílago en el tobillo es muy delgado. 
El seguimiento de los pacientes operados o de aquellos que reciben tratamiento conservador se realiza, de manera rutinaria, mediante las mismas modalidades que para el diagnóstico (radiografías, RM o TC), de preferencia, con la frecuencia más baja que sea clínicamente relevante. Las radiografías brindan muy poca información, mientras que las TC no son adecuadas para evaluar el tejido de reparación del cartílago y, en general, aumentan la carga de radiación y la RM es un estudio caro para repetirlo con cierta frecuencia.

La inyección de medio de contraste intrarticular tanto en la RM (artro-RM) (Figura 5) como en la TC (artro-TC) (Figuras 6-8) es, hoy en día, el examen más fiable para valorar el estado del cartílago hialino, ya que el medio de contraste articular distiende la cápsula articular y separa las superficies de contacto, lo que aumenta la sensibilidad y la especificidad. Lamentablemente es un método invasivo, pero tolerable, y la probabilidad de complicaciones es baja.

Se han propuesto varias adaptaciones a las imágenes para obtener imágenes indirectas de la calidad del cartílago. En la RM, se desarrollaron técnicas, como el mapeo T2 o la RM de cartílago (delayed gadolinium-enhanced MRI of cartilage, dGEMRIC) con inyección intravenosa de gadolinio. Mientras que el mapeo T2 está relacionado con el contenido de agua y la reacción con las fibras de colágeno en el cartílago, la dGEMRIC se basa en el contenido de glucosaminoglicanos en el cartílago. Las concentraciones de agua y glucosaminoglicanos disminuyen con la degeneración del cartílago. La ventaja del mapeo T2 sobre la dGEMRIC es que no requiere la administración de un medio de contraste intrarticular.

Como conclusión, la imagen clínica de rutina, en la actualidad, está restringida a las tomas convencionales de rayos X, TC y RM. Aunque se está intentando valorar las lesiones osteocondrales en forma no invasiva (mapeo T2 y dGEMRIC), los métodos más sensibles y específicos son la artro-RM y fundamentalmente la artro-TC con medio de contraste intrarticular. Sin embargo, como ya se señaló, existen numerosas sugerencias para los sistemas de imágenes y el uso de diferentes clasificaciones: Berndt y Harty (radiológica), Ferkel (TC), Anderson (RM), entre otros. Es necesario unificar sistemas de clasificación y mejorar la obtención de imágenes no invasivas que ofrezcan datos reproductivos morfológicos, cuantitativos y cualitativos que sean comparables a lo largo del tiempo para explorar el efecto sobre la reparación de las nuevas técnicas de tratamiento. Por lo tanto, el desafío para las imágenes clínicas consiste en definir un método, idealmente no invasivo, con parámetros de imágenes útiles que sean clínicamente relevantes.

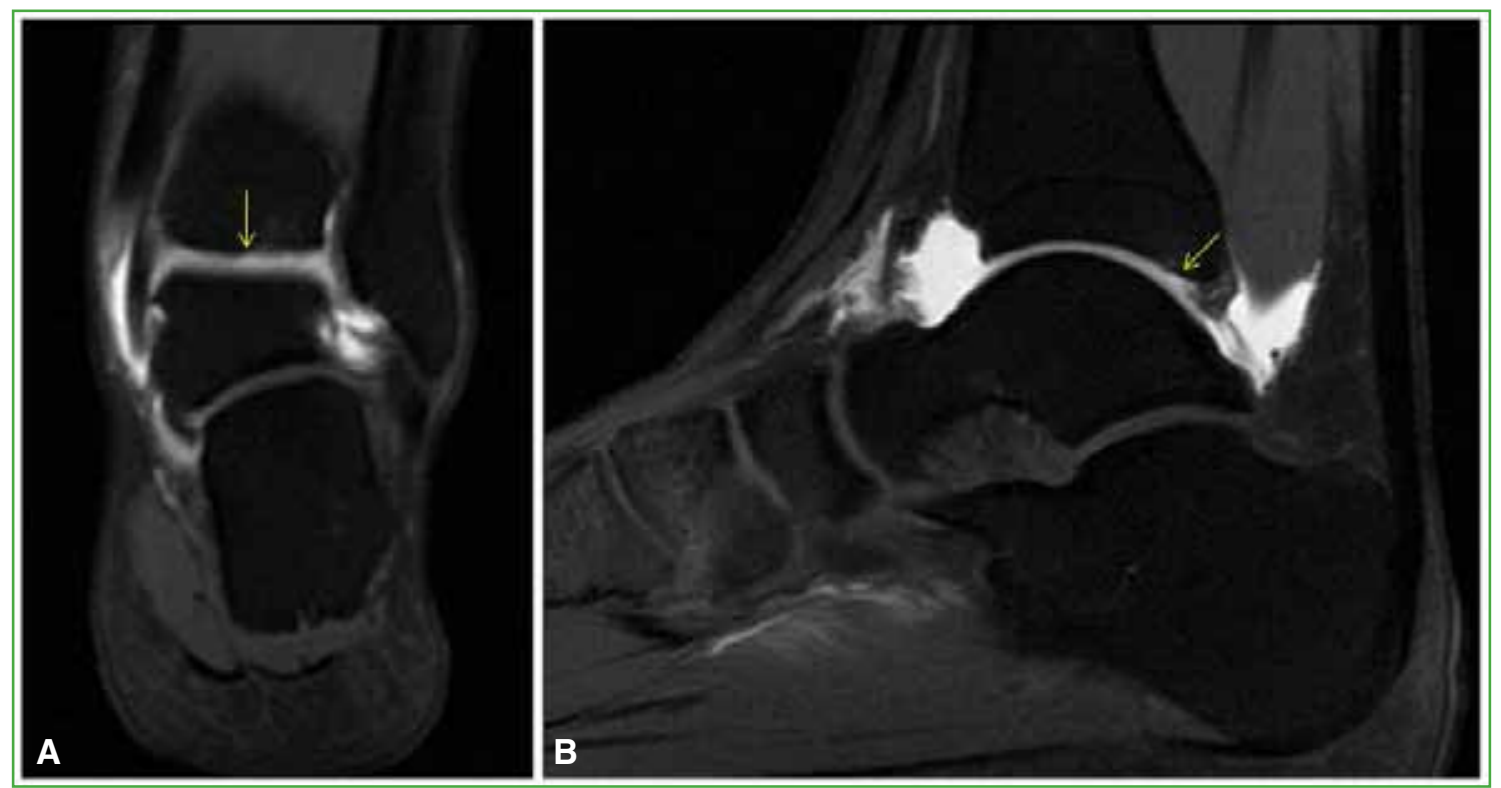

Figura 5. Artrorresonancia magnética de tobillo, planos coronal (A) y sagital (B). En este tipo de estudio, se inyecta un medio de contraste intrarticular para incrementar la sensibilidad y la especificidad. Se puede observar un pequeño defecto de cartílago hialino en el sector posterior de la superficie articular de la tibia que se llena de contraste. 


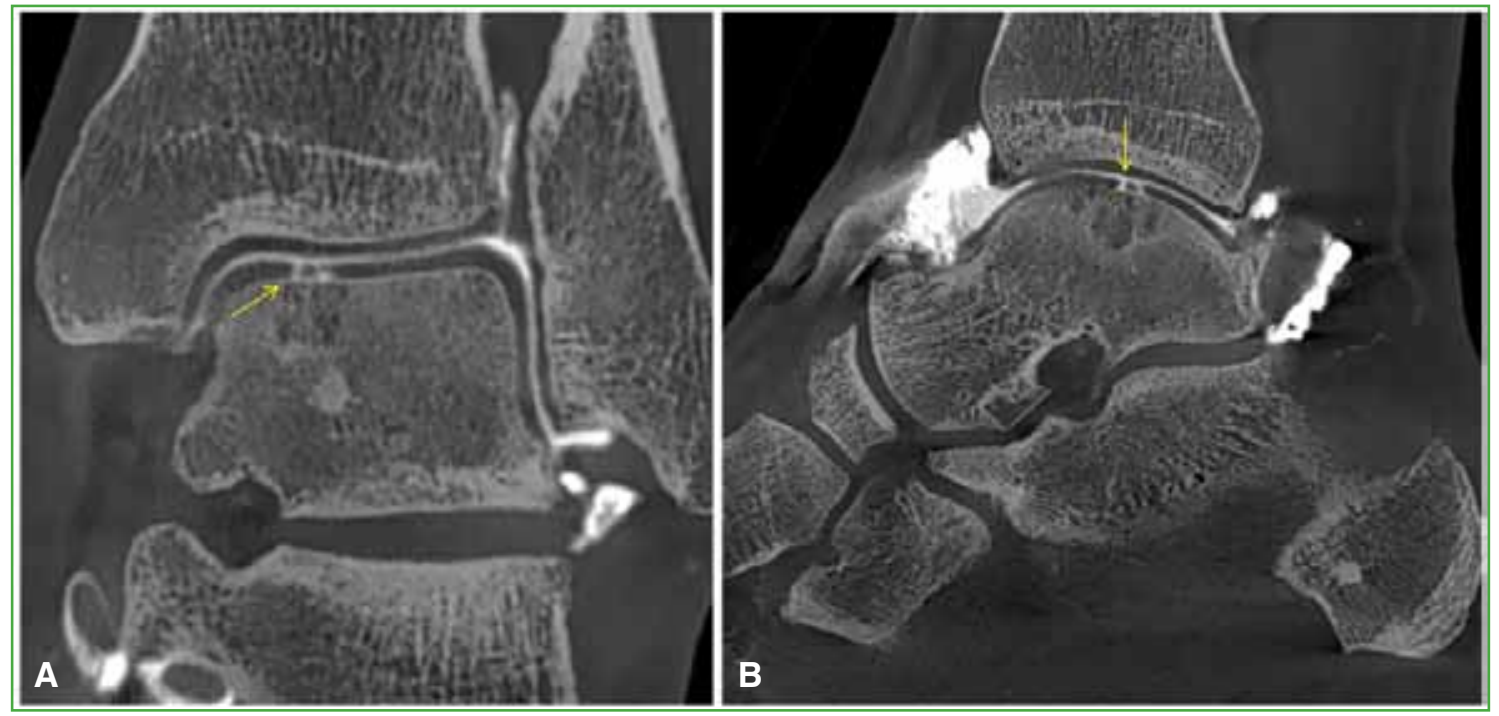

Figura 6. Artrotomografía de haz cónico, planos coronal (A) y sagital (B). Se reconocen dos trazos de fisura del cartílago hialino de la cúpula astragalina.
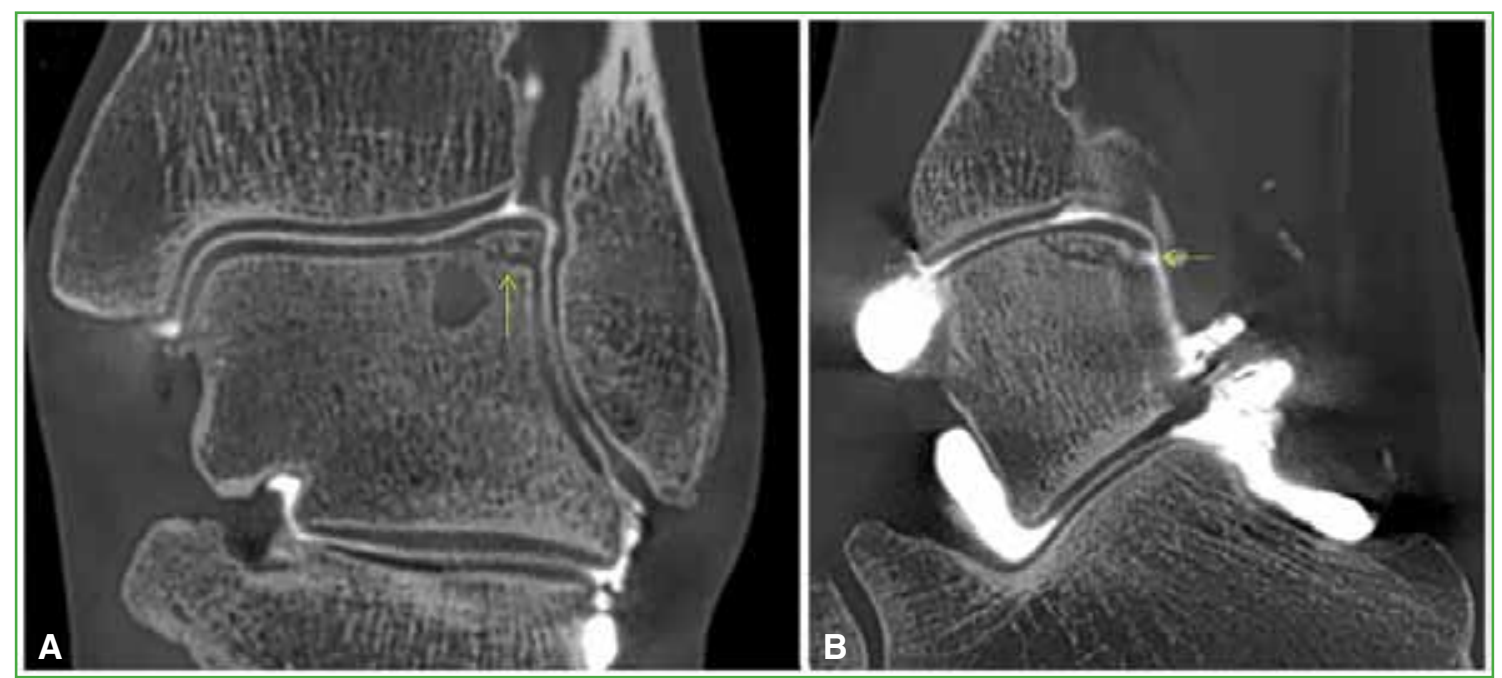

Figura 7. Artrotomografía de haz cónico, planos coronal (A) y sagital (B). Se observa una fractura del cartílago hialino en el sector posterior de la lesión osteocondral.
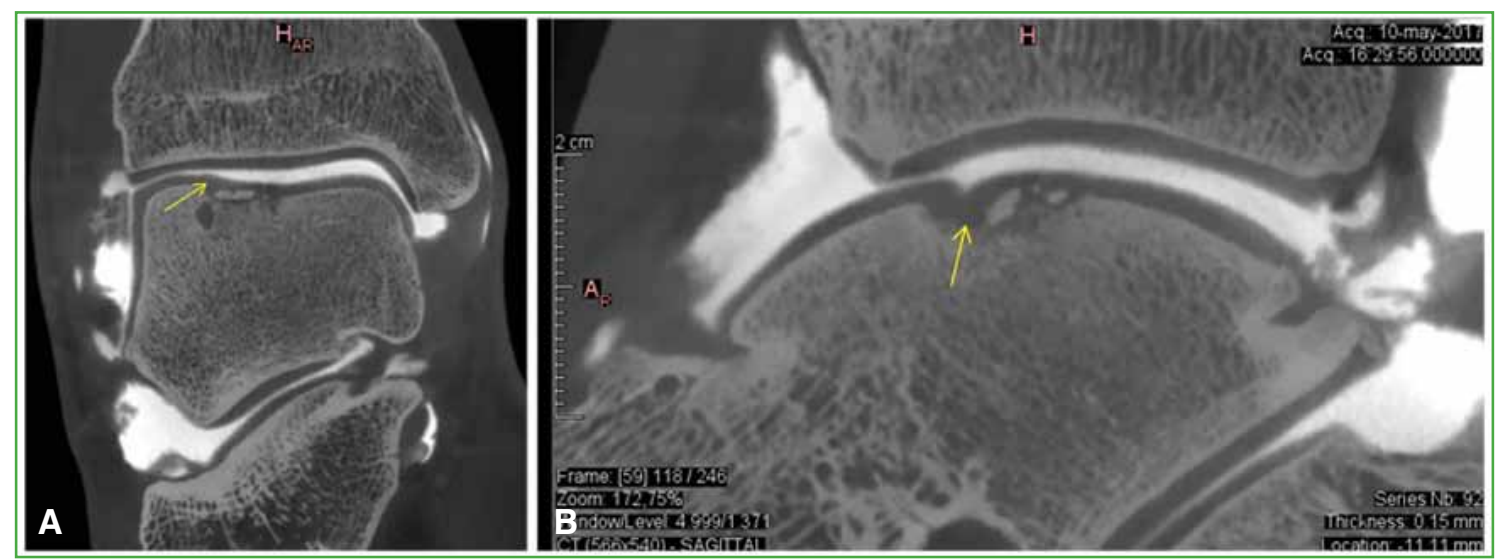

Figura 8. Artrotomografía de haz cónico, planos coronal (A) y sagital (B). Se visualiza un gran defecto óseo con fragmentación, pero completamente tapizado de cartílago hialino. 